\title{
Changes in Surface Roughness and Color Stability of Two Composites Caused by Different Bleaching Agents
}

\author{
Anna Paula Kalix França MENDES ${ }^{1}$ \\ Marcos de Oliveira BARCELEIRO ${ }^{2}$ \\ Rodrigo Sant'Anna Aguiar dos REIS ${ }^{3}$ \\ Lucilei Lopes BONATO ${ }^{4}$ \\ Kátia Regina Hostílio Cervantes DIAS ${ }^{1}$

\begin{abstract}
${ }^{1}$ Department of Dentistry, Dental School, UERJ - State University of Rio de Janeiro, Rio de Janeiro, RJ, Brazil ${ }^{2}$ Department of Dentistry, Dental School, UFF - Fluminense Federal University, Nova Friburgo, RJ, Brazil ${ }^{3}$ Department of Dental Materials, Dental School, UNIGRANRIO University, Duque de Caxias, RJ, Brazil ${ }^{4}$ Department of Dentistry, Dental School, UNITAU - University of Taubaté, Taubaté, SP, Brazil
\end{abstract}

\begin{abstract}
The objective of this study was to evaluate the effect of two bleaching agents ( $10 \%$ and $35 \%$ hydrogen peroxide) on the color stability and surface roughness of two composites, one nanohybrid and one nanoparticle. Specimens were polished, aged, stained, bleached and polished again. The action of the bleaching agents on the composites was analyzed using a profilometer (surface roughness) and a spectrophotometer (color stability). The effect of polishing the composites on the surface roughness and the resumption of the composite color was also evaluated. The results were analyzed statistically by ANOVA and Tukey's test at 5\% significance level. The analysis indicated that the nanohybrid composite was more affected by staining. The bleaching agents were not able to promote bleaching of either composite over the evaluation period. Surface polishing returned nanohybrid composite to its original color condition, which did not occur for the nanoparticle composite. Additionally, polishing did not return the surface roughness of either composite to its original value. It may be concluded that polishing surface after bleaching should not be the treatment of choice, as it was not possible to reverse the roughness of the composites to their original values, suggesting that a more extensive and irreversible degradation might have occurred.
\end{abstract}

Key Words: color stability, roughness, composite resins, bleaching.

\section{INTRODUCTION}

The use of dental bleaching agents to improve the esthetics of the natural dentition has become an increasingly popular procedure, especially after 1989 when home-assisted bleaching was introduced by Haywood and Heymann (1) and even more recently when at-home bleaching agents were made directly available to patients. (2) The constant search for ever whiter teeth and healthier smile is reflected by the increased sales of toothpastes, gels, chewing gum, bleaching wires/tapes and toothbrushes, all with ingredients that supposedly promote the bleaching of teeth (3).

The color of teeth may change due to the deposition of dyes on the surface of enamel (extrinsic pigmentation) or in combination with intrinsic tooth color, determined by the inner layers of dentin. Lighter color teeth can then be achieved by the use of toothpastes containing abrasive systems that remove or reduce the deposition of extrinsic dyes, or the use of bleaching agents such as peroxides, which are able to act internally by changing the color of dentin (3).

Currently, there are three basic substances used for bleaching teeth: hydrogen peroxide (HP), carbamide peroxide $(\mathrm{CP})$ and sodium perborate. It has been proposed that HP is what acts on the pigmenting factors. It is believed that bleaching occurs by oxidation of organic substances present in the tooth, caused by

Correspondence: Prof. Dr. Marcos de Oliveira Barceleiro, Departamento de Formação Específica, Faculdade de Odontologia de Nova Friburgo, Universidade Federal Fluminense, Rua Dr. Silvio Henrique Braune, 22, 28625-650 Nova Friburgo, RJ, Brasil. Tel: +55-22-2528-7166. Fax: +55-222528-7168. e-mail: marcosbarceleiro@gmail.com 
the free radicals (nitrogen) generated by the bleaching agent (4).

Much has been investigated on the changes in surface morphology of teeth $(5,6)$ and restorative materials, as well as changes with regard to their chemical, physical and mechanical properties caused by peroxide bleaching. Some studies have shown a significant increase in surface roughness and the amount of porosity in composites, asserting that resurfacing or replacement of the restorations is necessary after bleaching. $(7,8)$. However, other studies did not observe such changes in the surface or on the microhardness of composites. $(2,9,10)$. Regarding color change, it has been shown that HP is more effective at lightening composite materials when compared with $\mathrm{CP}$ at the same concentration (11) and it is also known that a nanoscale composite is more affected than a microhybrid composite when exposed to dyes, but this change can be reversed by bleaching (12).

At-home bleaching systems were recently introduced in the form of whitening strips $(6 \% \mathrm{HP}$, used $1 \mathrm{~h}$ per day for 14 days) and gel applied with a brush ( $18 \%$ CP, used 1 min per day for 3 weeks). Some studies using these materials reported that these two bleaching systems were able to alter the polishing of composite resins (13), but other studies showed that these materials do not change the surface morphology of composites $(2,14)$.

This divergence of opinions shows the importance of the evaluation of any new product based on peroxide introduced to the market, with regards to effects on dental tissues and restorative materials. Considering that the potential changes induced by bleaching agents may be clinically significant enough to compromise the integrity of restorations and to determine even the need of their replacement, and considering that it is necessary to know if only surface polishing is able to return the composite to its original condition, this study evaluated the effect of two HP bleaching systems, one administrated by the patient and the other applied inoffice, on the color change and surface roughness of two composites. This study also assessed the effects of post-bleaching polishing on regaining the initial surface roughness and color.

\section{MATERIAL AND METHODS}

\section{Preparation of Samples}

An array of depressions, $21.0 \mathrm{~mm}$ in diameter and $2.00 \mathrm{~mm}$ deep, was made from stainless steel. The composites listed in Table 1 were placed into the depressions in a single increment, with the outer surfaces coated with $4 \times 4 \mathrm{~cm}$ polyester sheets and between two steel plates of the same size. Pressure was applied with a press, to eliminate air bubbles and obtain an external surface free of coarse irregularities. Curing of the materials was performed with a halogen light for laboratory use (Triad 2000; DeguDent, Frankfurt, Germany) composed of 4 bulbs totaling $600 \mathrm{~W}$, with each surface cured for $1 \mathrm{~min}$.

Twenty specimens, 10 from each composite, were prepared using the above described technique. The specimens were kept in artificial saliva in an incubator at $37^{\circ} \mathrm{C}$ for $24 \mathrm{~h}$ and had their surfaces finished with $220-$, 400-, 800-, 1200-grit silicon carbide papers in a polishing machine (APL 4; Arotec, São Paulo, SP, Brazil). Next, the specimens were polished with Sof-Lex discs (3M/ ESPE, St. Paul, MN, USA) mounted on an arbor in a handpiece (Dabi Atlante, Ribeirão Preto, SP, Brazil) in a decreasing order of abrasiveness (black, dark blue, medium blue and light blue) and using intermittent movements. To standardize this procedure, each disc was applied 12 times on each specimen, rotating the specimen $90^{\circ}$ after every 3 applications, for a total of 48 applications, since 4 granulations were used. Polishing continued using Enhance tips (Dentsply Ind. e Com. Ltda., Petrópolis, RJ, Brazil), which were changed after every 2 specimens, followed by use of felt discs mounted on a mandrel and Diamond R (FGM, Joinville, SC, Brazil) polishing paste for composites. After polishing, the samples were aged in an apparatus for accelerated

Table 1. Composites used in the experiment.

\begin{tabular}{lcccc}
\hline Composite & Manufacturer & Organic matrix & Inorganic matrix & Lot number \\
\hline TPH3 & Dentsply & $\begin{array}{c}\text { Urethane modified Bis-GMA } \\
\text { dimethacrylate and TEGDMA }\end{array}$ & $\begin{array}{c}\text { Barium boron aluminum silicate glass and barium } \\
\text { boron fluoro-aluminum silicate glass3 }\end{array}$ & 795043 \\
Z350 & 3M/ESPE & $\begin{array}{c}\text { Bis-GMA, UDMA, } \\
\text { TEGDMA and Bis-EMA }\end{array}$ & Silane-treated ceramic and silane-treated silica & 6 FU \\
\hline
\end{tabular}


aging, using ultraviolet light for $24 \mathrm{~h}$, according to the 7491 International Organization for Standardization (15). The specimens were then stained with coffee for 7 days, with the dye being changed daily. During this time, the specimens were kept in an incubator at $37^{\circ} \mathrm{C}$.

After 7 days, the specimens were subjected to two treatments of bleaching with HP: an in-office (35\% HP - Whiteness HP Maxx, FGM) and an at-home treatment (10\% HP - Rembrandt Whitening Pen; Oral B, São Paulo, SP, Brazil). Whiteness HP Maxx was used according to manufacturer's instructions, in two 15-min applications without the application of light, totaling $30 \mathrm{~min}$ per session. The in-office system was applied in two sessions, with an interval of 7 days between them. The Rembrandt Whitening Pen was applied for 14 consecutive days, also in two applications of $15 \mathrm{~min}$ each. After each application, the surfaces of the specimens were washed in water and dried with paper towels.

After the bleaching procedures, all specimens were polished again as described for the initial polishing (Sof-Lex discs, Enhance System and Polishing with Diamond R).

\section{Roughness Analysis}

The average roughness of the samples was evaluated using a SJ.201P Mitutoyo profilometer (Mitutoyo Corporation, Tokyo, Japan) during the following moments of the experiment: T0 - after preparation, $\mathrm{T} 1$ - after accelerated aging of samples for $24 \mathrm{~h}$ with ultraviolet light, T2 - after dye treatment, T3 - after bleaching and T4 - after polishing.

The $R a$ parameter (parameter determined by the sum of the absolute values of the ordinances in relation to the midline, divided by the number of orders in a given sampling length, determining the arithmetic mean of the absolute values of the effective ordinance profile) was determined for each sample. The profilometer tip touched each specimen and ran a distance of $25 \mathrm{~mm}$ for 12 readings, following a clockwise radial direction and an average was then obtained.

The results were treated statistically with ANOVA and Tukey's test at 5\% significance level.

\section{Stability Analysis of Color}

The samples were measured in a reflectance spectrophotometer (Lambda 35 UV/VIS; Perkin Elmer Instruments, Oak Ridge, TN, USA) at the same moments of surface roughness test. The results were printed in values and drawn on a graph $\mathrm{T}$ (transmittance) in a 400$700 \mathrm{~nm}$ range. The stability of color $(\Delta \mathrm{E})$ was measured using mirrors with $2^{\circ}$ and $10^{\circ}$ inclinations, and using the CIE $\mathrm{L}^{*} \mathrm{a}^{*} \mathrm{~b}^{*}$ color system. The only used angle was $2^{\circ}$. The CIE $\mathrm{L}^{*} \mathrm{a}^{*} \mathrm{~b}^{*}$ color system consists of an international standardization of colors that uses three coordinates to evaluate the colors. $L *$ indicates lightness (brightness) of a color, $\mathrm{a}^{*}$ describes the red-green content and $b^{*}$ the yellow-blue content.

The differences from the default values were calculated using the values of $\Delta \mathrm{L}^{*}, \Delta \mathrm{a}^{*}$ and $\Delta \mathrm{b}^{*}$. The total variation in color was calculated using the following formula:

$$
\Delta \mathrm{E}=\left[\left(\Delta \mathrm{L}^{*}\right)^{2}+\left(\Delta \mathrm{a}^{*}\right)^{2}+\left(\Delta \mathrm{b}^{*}\right)^{2}\right]^{1 / 2}
$$

Table 2. Results of Ra from the groups tested, using Whiteness $\mathrm{HP}$ and Rembrandt.

\begin{tabular}{|c|c|c|c|c|}
\hline Treatment & $\begin{array}{l}\text { Bleaching } \\
\text { product }\end{array}$ & $\begin{array}{l}\text { Composite } \\
(\mathrm{n}=5)\end{array}$ & $\begin{array}{c}\text { Average } \\
\mathrm{Ra}\end{array}$ & SD \\
\hline \multirow{4}{*}{ Initial } & Whiteness HP & ТPH3 & 0.200 & 0.060 \\
\hline & Whiteness HP & $\mathrm{Z} 350$ & 0.238 & 0.069 \\
\hline & Rembrandt & ТРH3 & 0.232 & 0.036 \\
\hline & Rembrandt & $\mathrm{Z350}$ & 0.232 & 0.059 \\
\hline \multirow{4}{*}{ Aging } & Whiteness HP & ТPH3 & 0.160 & 0.021 \\
\hline & Whiteness HP & $\mathrm{Z} 350$ & 0.222 & 0.076 \\
\hline & Rembrandt & ТPH3 & 0.204 & 0.032 \\
\hline & Rembrandt & $\mathrm{Z} 350$ & 0.248 & 0.072 \\
\hline \multirow{4}{*}{ Dye } & Whiteness HP & ТPH3 & 0.188 & 0.054 \\
\hline & Whiteness HP & $\mathrm{Z} 350$ & 0.236 & 0.072 \\
\hline & Rembrandt & ТPH3 & 0.204 & 0.023 \\
\hline & Rembrandt & $\mathrm{Z} 350$ & 0.232 & 0.051 \\
\hline \multirow{4}{*}{ Bleaching } & Whiteness HP & ТPH3 & 0.178 & 0.025 \\
\hline & Whiteness HP & $\mathrm{Z350}$ & 0.294 & 0.077 \\
\hline & Rembrandt & ТPH3 & 0.216 & 0.051 \\
\hline & Rembrandt & $\mathrm{Z} 350$ & 0.346 & 0.075 \\
\hline \multirow{4}{*}{ Polishing } & Whiteness HP & ТPH3 & 0.306 & 0.043 \\
\hline & Whiteness HP & $\mathrm{Z} 350$ & 0.364 & 0.055 \\
\hline & Rembrandt & ТРН3 & 0.264 & 0.119 \\
\hline & Rembrandt & $\mathrm{Z350}$ & 0.316 & 0.065 \\
\hline
\end{tabular}


where: $\Delta \mathrm{L}^{*}=\mathrm{L}_{\mathrm{o}}-\mathrm{L}_{1}, \Delta \mathrm{a}^{*}=\mathrm{a}_{\mathrm{o}}-\mathrm{a}_{1}$ and $\Delta \mathrm{b}^{*}=\mathrm{b}_{\mathrm{o}}-\mathrm{b}_{1}$ $(\mathrm{o}=$ initial value and $1=$ final value $)$

The clinical significance for the stability of color was determined using the criteria presented by Seghi et al. (16) and adapted by Reis et al. (17) for analysis of color change. When the $\Delta \mathrm{E}$ was higher than 3.7 , it was considered an easily visible difference. When $\Delta \mathrm{E}$ was between 3.7 and 1 , it was considered a clinically acceptable difference, and when the result was less than 1 , the difference was considered clinically not visible.

The average values of color stability $(\Delta \mathrm{E})$ were compared using ANOVA and differences between the groups were treated statistically with Tukey's test at 5\% significance level.

\section{RESULTS}

\section{Roughness Test}

Table 2 shows the results for $R a$ from the tested groups. In the analysis of results obtained with Whiteness

Table 3. Average DE - Composite (Coffee + Bleaching agent) compared to control group.

\begin{tabular}{|c|c|c|c|c|c|}
\hline Treatment & $\begin{array}{l}\text { Composite } \\
(n=5)\end{array}$ & $\begin{array}{c}\text { Bleaching } \\
\text { agent }\end{array}$ & $\begin{array}{c}\text { Average } \\
\text { DE }\end{array}$ & SD & $\begin{array}{c}\text { Clinical } \\
\text { significance }\end{array}$ \\
\hline \multirow{4}{*}{ Aging } & ТPH3 & Whiteness HP & $2.391 \mathrm{~A}$ & 1.128 & CAD \\
\hline & $\mathrm{Z} 350$ & Whiteness HP & $1.454 \mathrm{~A}$ & 0.344 & CAD \\
\hline & ТРH3 & Rembrandt & $2.727 \mathrm{~A}$ & 1.744 & CAD \\
\hline & $\mathrm{Z} 350$ & Rembrandt & $2.138 \mathrm{~A}$ & 0.618 & CAD \\
\hline \multirow{4}{*}{ Dye } & ТPH3 & Whiteness HP & $4.501 \mathrm{~B}$ & 0.544 & EVD \\
\hline & $\mathrm{Z} 350$ & Whiteness HP & $2.026 \mathrm{AB}$ & 0.402 & CAD \\
\hline & ТPH3 & Rembrandt & $3.653 \mathrm{AB}$ & 0.978 & CAD \\
\hline & $\mathrm{Z} 350$ & Rembrandt & $2.115 \mathrm{~A}$ & 0.389 & CAD \\
\hline \multirow{4}{*}{$\begin{array}{c}\text { Bleaching } \\
\text { Agent }\end{array}$} & ТРН3 & Whiteness HP & $5.094 \mathrm{~B}$ & 0.805 & EVD \\
\hline & Z350 & Whiteness HP & $4.535 \mathrm{C}$ & 0.332 & EVD \\
\hline & ТPH3 & Rembrandt & $4.697 \mathrm{~B}$ & 0.696 & EVD \\
\hline & $\mathrm{Z} 350$ & Rembrandt & $3.616 \mathrm{~B}$ & 0.781 & CAD \\
\hline \multirow{4}{*}{ Polishing } & ТРН3 & Whiteness HP & $2.443 \mathrm{~A}$ & 0.767 & CAD \\
\hline & $\mathrm{Z} 350$ & Whiteness HP & $3.106 \mathrm{~B}$ & 1.065 & CAD \\
\hline & ТРН3 & Rembrandt & $2.774 \mathrm{~A}$ & 0.484 & CAD \\
\hline & $\mathrm{Z} 350$ & Rembrandt & $3.693 \mathrm{~B}$ & 0.638 & CAD \\
\hline
\end{tabular}

$* \mathrm{CAD}=$ Clinically acceptable difference $; \mathrm{EVD}=$ Easily visible difference
HP bleaching, the ANOVA and Tukey's test showed that polishing was the only treatment that showed significantly different results $(\mathrm{p}<0.05)$. However, when using the Rembrandt whitening, no statistically significant differences $(p>0.05)$ were found in either group.

\section{Color Stability Analysis}

Table 3 and Figures 1 and 2 show the results of $\Delta \mathrm{E}$ from the two tested groups.

Table 3 shows that the results from the aging treatments and polishing did not differ from each other with the combination of TPH3 and Whiteness HP, while the coloring and bleaching treatments, although not differing, presented significant differences compared with previous treatments when classified using the criteria presented by Seghi et al. (16) and adapted by Reis et al. (17) for analysis of color change. Analyzing the parameters of color using the $\mathrm{L}^{*} \mathrm{a}^{*} \mathrm{~b}^{*}$ coordinates, there was a decrease in brightness of TPH3 when aged and stained, the same increase when cleared and polished (Fig. 1A) with a trend to greenyellow (Fig. 1B and 1C).

Table 3 also shows that the aging treatments and dye were statistically similar, as were the treatments for coloring and polishing, with only the bleaching treatment showing statistically different results $(\mathrm{p}<0.05)$, with the association Z350 and Whiteness HP. Regarding the analysis of color parameters, there was an increase of brightness (Fig. 1A) and a tendency to a blue-green color for composite Z350 (Fig. 1B and 1C).

In Table 3, it can be seen that there is no significant difference $(p>0.05)$ between the aging treatments, coloring and polishing, with the combination of TPH 3 and Rembrandt. Coloring and bleaching, although not statistically different between each other $(p>0.05)$, differed significantly from the other values $(p<0.05)$. Analysis of the $L^{*} a^{*}$ and $b^{*}$ parameters show an increase of luminosity (Fig. 2A) and 
a tendency to green-yellow (Fig. 2B and 2C).

Finally, Table 3 also demonstrates no significant differences between the treatments of aging and color $(\mathrm{p}>0.05)$, but a statistically significant difference $(p<0.05)$ in the polishing and bleaching treatments, with the association Z350 and Rembrandt. ANOVA showed differences between groups. These differences were confirmed by the Tukey's test. For Z350 in all
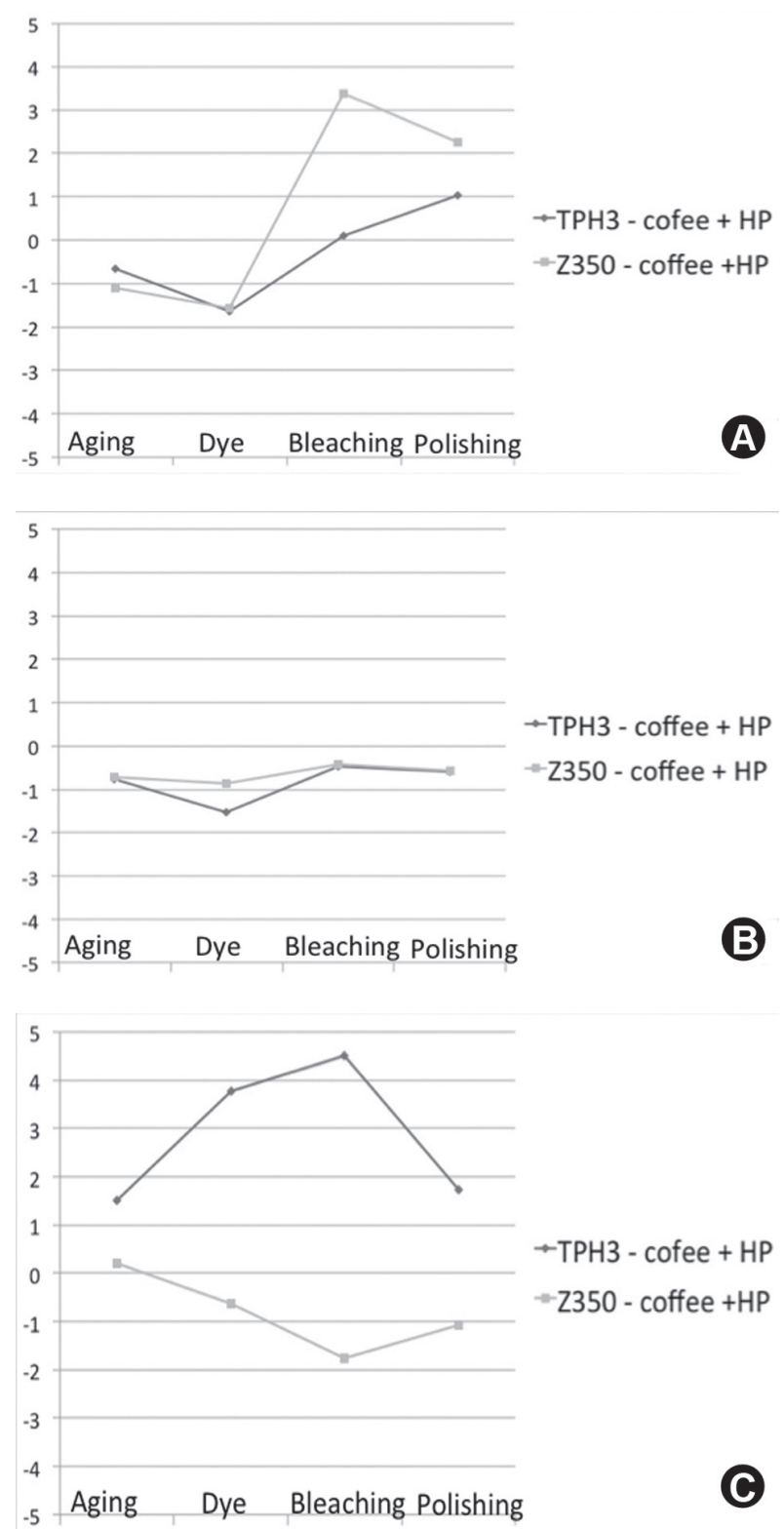

Figure 1. Results of $\Delta \mathrm{E}$ from the coffee $+\mathrm{HP}$ group. A: Composite's $\Delta \mathrm{L}$ after different treatments (Lightness values: $+\mathrm{L}=$ white, $-\mathrm{L}=$ black). B: Composite's $\Delta$ a comparing to T0 (redgreen values: $+\mathrm{a}=$ red, $-\mathrm{a}=$ green). $\mathrm{C}$ : Composite's $\Delta \mathrm{b}$ comparing to T0 (yellow-blue values: $+b=$ yellow, $-b=b l u e$ ). treatments, $\Delta \mathrm{E}$ was considered clinically acceptable, with an increase in brightness (Fig. 2A) and a tendency to green-blue (Fig. 2B and 2C).

\section{DISCUSSION}

Color changes in direct restorative materials, more specifically in composite resins, have a direct influence
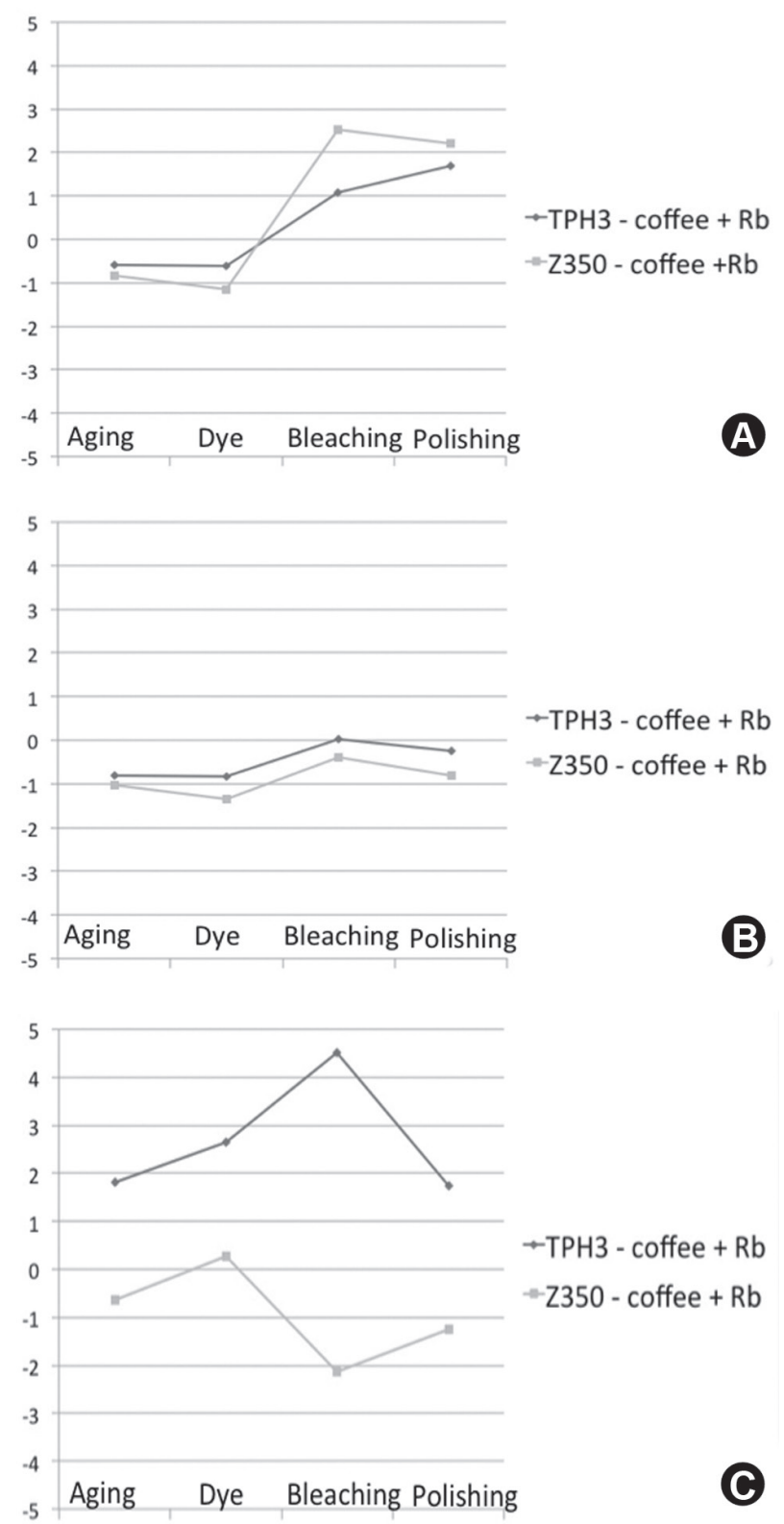

Figure 2. Results of $\Delta \mathrm{E}$ from the coffee $+\mathrm{Rb}$ group. A: Composite's $\Delta \mathrm{L}$ after different treatments (Lightness values: $+\mathrm{L}=$ white, -L=black). B: Composite's $\Delta$ a comparing to $\mathrm{T} 0$ (red-green values: $+\mathrm{a}=\mathrm{red}, \mathrm{a}=$ green). $\mathrm{C}$ : Composite's $\Delta \mathrm{b}$ comparing to $\mathrm{T} 0$ (yellowblue values: $+\mathrm{b}=$ yellow, $-\mathrm{b}=$ blue). 
on the aesthetics, therefore on the clinical longevity of a restoration. Composite resins have a wide variety of organic compounds that can contribute to intrinsic discoloration. Particularly in this study, the different color changes observed between the composites can be explained by their different chemical compositions (Table 1). This difference was also found by other studies, such as those by Vilalta et al. (12), which related this color change to factors intrinsic to the material, like their chemical composition (quality and quantity of organic matrix, type and amount of inorganic filler, the used photoinitiator agent, degree of monomer conversion). Extrinsic factors related to the environment (medium used for maintenance of the samples), exposure to dyes and other chemical agents (such as bleaching), are other important factors, but have their actions modulated by the susceptibility of a composite to degradation (also related to its composition) and the time factor (8).

The difference in composition between the composite materials can determine the difference in behavior regarding the used dye (surface staining). In general, TPH3 was significantly affected by the dye, producing color changes that ranged from easily visible changes $(\Delta E>3.7)$ to a clinically acceptable difference $(\Delta \mathrm{E}<3.7)$. As for $\mathrm{Z350}$, these color changes were less evident, as indicated by the low values of $\Delta \mathrm{E}$ and classified clinically in most treatments as a clinically acceptable difference $(\Delta \mathrm{E}<3.7)$. These differences in color change may be related to the size and distribution of the filler material, since the two composites have almost the same volume of filler material (Z350 - 59.5\% and TPH $3-58 \%$ ). It is known, through the use of a qualitative microstructural characterization performed by Mayworm (18), that TPH3 has smaller particles than Filtek Z350, due to the presence of nanoclusters. Therefore, for the same volume, a smaller particle size would present a greater surface area in contact with the matrix. Thus, according to the present results, TPH3 may have a greater particle surface area, or in other words, a larger area of interface between particle-matrix composite, possibly making it more susceptible to discoloration by the sorption of dyes. There was also a gradual decrease in brightness for both aging and subsequent application of colors and a tendency to a green-yellow color for TPH3 and a blue-green color for $\mathrm{Z} 350$. Positive values for the $b^{*}$ color coordinate in the case of TPH 3 show increasing chroma and saturation as opposed to the negative values found for Z350. These data confirm the direct relationship between changes in color $(\Delta \mathrm{E})$ and $\mathrm{b}^{*}$ color coordinate, a correlation also presented by Uchida et al (19). In the present study, the larger variations in color $(\Delta \mathrm{E})$ were directly related to an increase in variation of $\mathrm{b} *$ color coordinate, as evidenced by the tendency of TPH3 to yellowing.

In the current study, bleaching agents based on HP were not able to promote some kind of brightness for the evaluated composites over time, unlike other studies (11) where this bleaching was observed.

There was an increase of coordinate $\mathrm{L}^{*}$ (brightness) for Z350 when compared with the brightness of TPH3, but with maintenance of other parameters relative to the $a^{*}$ and $b^{*}$ constants. Despite the increase in brightness that was evident for both composites, this parameter alone was not conclusive or decisive for the description of color, since color can only be described in three dimensions. This statement is corroborated by Lim et al. (20), who concluded that the correlation between the contents of cargo, chroma and value is moderate, despite a direct relationship between content loading, scattering coefficient (S) and reflected light (IR). Variations of $\Delta \mathrm{E}$ can be explained by storage in artificial saliva at $37^{\circ} \mathrm{C}$ after the application of dyes.

When evaluating the polishing treatment after bleaching, there was clearly a return to the initial condition for the aged TPH3 composite, which was not the case for Z350. This result suggests that, although the bleaching agent was not effective in bleaching, it might have generated irreversible changes of the surface roughness, possibly related to the structural portion of the composite, occurring in the crystalline structures of the composites (21). The degradation of the crystalline structure of the composite changes the reflection of light, which is clinically translated as color variation.

Accelerated aging in artificial saliva for both composites promoted a decrease in roughness when compared with the initial surface polishing, as evidenced by the slight decrease in values of $R a$. It was proposed that this surface change occurred in the post-curing polymeric materials due to temperature and the time of exposure, a fact indicated in a study by Mayworm (18). Dye had no influence on the roughness and the used bleaching product when evaluated in isolation, evidenced no changes in roughness as well.

In most studies, the deleterious action of bleaching agents on the enamel $(5,6)$ and composites $(7,8,21)$ was shown by an increase in surface roughness and a reduction of microhardness. In this study, the bleaching treatment showed no significant changes in surface 
roughness of both composites, which agrees with Duschner et al. (22) and Silva et al. (14).

Polishing after bleaching was found to be statistically different only with TPH3 treated with coffee + HP and Z350 treated with coffee + HP, with an inability to return to the initial roughness, suggesting that there was an irreversible change of the composite structure of the organic matrix (10) or its crystalline phase (21) by hydrolytic degradation. Although the changes were not considered statistically significant for the groups where polishing after bleaching occurred, the possibility of obvious change in roughness cannot be ruled out, as the changes might have been small and may not have been detected by the profilometer sensor (digital profilometer).

Based on these findings, the total replacement or repair of a composite in the anterior region after it is subjected to bleaching procedures is recommended. The repair should not be restricted only to the superficial layer of the composite, but rather cover a part of the intermediate portion thereof, as the depth of the changes caused by contact with the bleaching agent is not yet properly established. Additionally, polishing surface after bleaching should not be the treatment of choice, as it was not possible to reverse the roughness of the composites to their original value, suggesting that a more extensive and irreversible degradation may have occurred.

Considering the results of the present study, HP bleaching agents were not able to promote an effective bleaching of composite materials at the studied times and produced significant changes in the roughness. Additionally, polishing after bleaching returned TPH3 to the initial color of the composite, which was not possible for Z350, but did not return either composite material to the initial surface roughness.

\section{RESUMO}

O objetivo deste estudo foi avaliar o efeito de dois agentes clareadores (peróxido de hidrogênio a $10 \%$ e $35 \%$ ) sobre a estabilidade de cor e rugosidade superficial de dois compósitos, um nanohíbrido e um nanoparticulado. Os espécimes foram polidos, envelhecidos, manchados, clareados e polidos novamente. A ação dos agentes clareadores sobre os compósitos foi analisada em perfilômetro (rugosidade) e um espectrofotômetro (estabilidade de cor). A ação de polimento dos compósitos sobre a rugosidade superficial e a retomada da cor dos compósitos também foi avaliada. Os resultados foram analisados estatisticamente por ANOVA e teste de Tukey ( $5 \%$ de significância). A análise indicou que o compósito nanohíbrido foi mais afetado pelo manchamento. Os agentes clareadores não foram capazes de promover o clareamento dos compósitos ao longo do período de avaliação. O polimento da superfície retornou o compósito nanohíbrido à sua condição de cor original, o que não foi observado para o nanoparticulado. Além disso, o polimento não retornou a rugosidade de superfície dos compósitos para os valores originais. Os autores concluíram que o polimento da superfície após o clareamento não deve ser a opção de tratamento, uma vez que não foi possível inverter a rugosidade dos compósitos à sua rugosidade original, sugerindo que uma degradação mais extensa e irreversível pode ter ocorrido.

\section{REFERENCES}

1. Haywood VB, Heymann HO. Nightguard vital bleaching: how safe it is? Quint Int 1991;22:515-523.

2. Schemehorn B, Gonzalez-Cabezas C, Joiner A. A SEM evaluation of a $6 \%$ hydrogen peroxide tooth whitening gel on dental materials in vitro. J Dent 2004;32(suppl.1):35-39.

3. Collins LZ, Maggio B, Liebman J, Blanck M, Lefort S, Waterfield $\mathrm{P}$, et al.. Clinical evaluation of a novel whitening gel, containing $6 \%$ hydrogen peroxide and a standard fluoride toothpaste. J Dent 2004;32(suppl. 1):13-17.

4. Joiner A. The bleaching of teeth: a review of literature. J Dent 2006;34:412-419.

5. de Oliveira R, Paes Leme AF, Giannini M. Effect of a carbamide peroxide bleaching gel containing calcium or fluoride on human enamel surface microhardness. Braz Dent J 2005;16:103-106.

6. Berger SB, Pavan S, Santos PH, Giannini M, Bedran-Russo AK. Effect of bleaching on sound enamel and with early artificial caries lesions using confocal laser microscopy. Braz Dent J 2012;23:110115.

7. de Andrade IC, Basting RT, Lima-Arsati YB, do Amaral FL, Rodrigues JA, França FM. Surface roughness evaluation and shade changes of a nanofilled resin composite after bleaching and immersion in staining solutions. Am J Dent 2011;24:245-249.

8. Wang L, Francisconi LF, Atta MT, Dos Santos JR, Del Padre NC, Gonini A Júnior, et al.. Effect of bleaching gels on surface roughness of nanofilled composite resins. Eur J Dent 2011;5:173179.

9. Polydorou O, Mönting JS, Hellwig E, Auschill TM. Effect of inoffice tooth bleaching on the microhardness of six dental esthetic restorative materials. Dent Mater 2007;23:153-158.

10. Polydorou O, Beiter J, König A, Hellwig E, Kümmerer K. Effect of bleaching on the elution of monomers from modern dental composite materials. Dent Mater 2009;25:254-260.

11. Canay S, Cehreli M. The effect of current bleaching agents on the color of light- polymerized composites in vitro. J Prosth Dent 2003;89:474-478.

12. Villalta P, Lu H, Okte Z, Garcia-Godoy F, Powers JM. Effects of staining and bleaching on color change of dental composite resins. J Prosth Dent 2006;95:137-142.

13. Yalcin F, Gurgan S. Effect of two different bleaching regimens on the gloss of tooth colored restorative materials. Dent Mater 2004;21:464-468.

14. Silva MF, Davies RM, Stewart B, DeVizio W, Tonholo J, da Silva Júnior JG, et al.. Effect of whitening gels on the surface roughness of restorative materials in situ. Dent Mater 2006;22:919-924.

15. International Organization for Standardization. International standard ISO 7491:2000: dental materials - determination of colour stability. 2. ed. Geneve: ISO, 2000.

16. Seghi RR, Johnston WM, O`brien WJ. Spectrophotometric analysis of color differences between porcelain systems. J Prosth Dent 1986;56:35-40.

17. Reis RS, Neiva GF, Yaman P, Razzoog ME. Effect of firing on 
the color stability of a light-cured ceramic stain. J Prosthodont 1996;5:182-185.

18. Mayworm CD, Camargo SS Jr, Bastian FL. Influence of artificial saliva on abrasive wear and microhardness of dental composites filled with nanoparticles. J Dent 2008;36:703-710.

19. Uchida H, Vaidyanathan J, Viswanadhan T, Vaidyanathan TK. Color stability of dental composites as a function of shade. J Prosth Dent 1998;79:372-377.

20. Lim YK, Lee YK, Lim BS, Rhee SH, Yang HC. Influence of filler distribution on the color parameters of experimental resin composites. Dent Mater 2008;24:67-73.
21. Gurgan S, Yalcin F. The effect of 2 different bleaching regimens on the surface roughness and hardness of tooth-colored restorative materials. Quint Int 2007;38:83-87.

22. Duschner H, Götz H, White DJ, Kozak KM, Zoladz JR. Effects of hydrogen peroxide bleaching strip gels on dental restorative materials in vitro: surface microhardness and surface morphology. J Clin Dent 2004;4:105-115.

ReceivedNOvember 13, 2011

Accepted September 30,2012 